\title{
Nitrous Oxide Sedation and Bispectral Index
}

\author{
Berrin ISIKa, MD \\ Tamer TÜZÜNER \\ Melih TEZKIRECIOḠLUb \\ Nurhan ÖZTAŞc, DDS, PhD
}

\begin{abstract}
Objectives: To determine whether bispectral analysis (BIS) changes during nitrous oxide $\left(\mathrm{N}_{2} \mathrm{O}\right)$ sedation in anxious children undergoing extraction of primary teeth.

Methods: In this prospective study 45, ASA physical status I children, aged between 7 to 12 years and scheduled for primary teeth extraction under $\mathrm{N}_{2} \mathrm{O} / \mathrm{O}_{2}$ sedation are included. At baseline (TO) and during the sedation procedure (T1-6); BIS levels, Ramsay Sedation Scores (RSS), oxygen saturation $\left(\mathrm{SpO}_{2}\right)$, and heart rate (HR) were recorded at one-minute intervals. Forty percent $\mathrm{N}_{2} \mathrm{O}$ in $\mathrm{O}_{2}$ was given by a nasal hood, and $\mathrm{N}_{2} \mathrm{O}$ concentration was enhanced to $60 \%$ in a two-minute period. Paired measurements of BIS levels with Observer's Assessment of Alertness and Sedation (OAA/S) scores were obtained during sedation procedure.

Results: Since 5 patients refused application of the nasal hood, a total 40 of the original 45 subjects completed the study. Mean age and weight of the children were $9.5 \pm 1.4$ years and $23.7 \pm$ $9.7 \mathrm{~kg}$, respectively. Nitrous oxide inhalation produced no changes in BIS levels despite a sedation level in OAA/S scores were observed at $40-60 \% \mathrm{~N}_{2} \mathrm{O}$ concentrations.

Conclusions: BIS values do not change during $\mathrm{N}_{2} \mathrm{O} / \mathrm{O}_{2}$ sedation and the BIS monitor is not appropriate to evaluate the depth of sedation provided by $\mathrm{N}_{2} \mathrm{O} / \mathrm{O}_{2}$ during primary teeth extraction in children. (Eur J Dent 2007;1:240-245)
\end{abstract}

Key Words: Nitrous oxide sedation; Bispectral index; Anxiety; Ramsay sedation scale.

\section{INTRODUCTION}

Some children need sedation because of fear or anxiety in pediatric dentistry. ${ }^{1-3}$ In pediatric dental

a Anesthesiology and Reanimation Specialist, Gazi University, Faculty of Dentistry, Department Oral and Maxillofacial Surgery, Ankara, TURKEY

b Research Assistant, Gazi University,

Faculty of Dentistry, Department of Pediatric Dentistry, Ankara, TURKEY

Gazi University, Faculty of Dentistry,

Department of Pediatric Dentistry, Ankara, TURKEY

-

Corresponding Author: Dr. Berrin IȘIK

Assistant Professor, Anesthesiology and Reanimation Specialist Gazi University Faculty of Dentistry,

Department Oral and Maxillofacial Surgery

06510 Emek Ankara/TURKEY

Phone: + 903122034048 + 905054667192

E-mail: berrinisik@gazi.edu.tr

berrin_isikamynet.com practice, for which analgesia is accomplished by local or regional anesthesia, sedation application is considerably different from medical practice..$^{1-5}$ To assess the depth of the sedation, physiological signs such as heart rate, blood pressure, and respiratory rate are important. But physiological signs exhibit large inter-patient variability and are quite dependent on the medications used. Also, they are only indirect expressions of the drugs' effects on the brain and other major systems. The use of sedation scales is the most frequent method of quantifying the sedative effect. Most commonly, subjective clinical scoring methods are used. ${ }^{5-7}$ The most popular is the Observer's Assessment of Alertness and Sedation (OAA/S) scale (Table 1). ${ }^{8-10}$ It measures the level of alertness in sedated 
subjects based on the assessment of 4 categories: responsiveness, speech, facial expression and ocular appearance. Also, the Ramsay Sedation Scale (RSS) ${ }^{11}$ (Table 2) is well established for the evaluation of sedation. It is easy and inexpensive to perform. But sedation scales are not objective methods. The bispectral index (BIS) offers a potential alternative to subjective scales when they do not work well or may not be sufficiently sensitive to evaluate sedation level. Bispectral index is a processed electroencephalographic (EEG) parameter, expressed as a numeric value ranging from 0 (isoelectric) to 100 (awake with eyes open) that is used clinically as a measure of hypnosis. It is currently used most commonly intraoperatively to monitor the effects of anesthetic and sedative agents as a means of judging the depth of sedation or anesthesia. ${ }^{12,13}$ Bispectral index monitoring is suggested to non anesthesiologist in order to avoid too deep sedation. ${ }^{14}$ Some studies have shown a significant correlation between BIS and OAA/S scores by using different sedative drugs with $\mathrm{N}_{2} \mathrm{O} / \mathrm{O}_{2}$, but others have shown that $\mathrm{N}_{2} \mathrm{O}$ has no effect on BIS in human volunteers when used solely. ${ }^{10,13,15,16}$ The other researchers showed that paradoxical changes might occur at BIS values during induction of anesthesia. ${ }^{13,17-19}$ Although $\mathrm{N}_{2} \mathrm{O}$ has been widely used as an anesthetic adjuvant, its effect on EEG activity is poorly understood because it is usually studied in the presence of additional anesthetics, including inhaled anesthetics. Leduc et al ${ }^{20}$ showed that $\mathrm{N}_{2} \mathrm{O} / \mathrm{O}_{2}$ at peri-MAC partial

Table 1. Observer's Assessment of Alertness/Sedation (OAA/S) Scale.

\begin{tabular}{|c|c|c|c|c|}
\hline Responsiveness & Speech & $\begin{array}{c}\text { Facial } \\
\text { expression }\end{array}$ & Eyes & Score \\
\hline $\begin{array}{l}\text { Responds readily to name } \\
\text { spoken in normal tone }\end{array}$ & Normal & Normal & Clear, no ptosis & 5 \\
\hline $\begin{array}{l}\text { Lethargic response to name } \\
\text { spoken in normal tone }\end{array}$ & $\begin{array}{l}\text { Mild slowing or } \\
\text { thickening }\end{array}$ & $\begin{array}{l}\text { Mild } \\
\text { relaxation }\end{array}$ & $\begin{array}{l}\text { Glazed or mild ptosis } \\
\text { (less than half the eye) }\end{array}$ & 4 \\
\hline $\begin{array}{l}\text { Responds only after name is } \\
\text { called loudly or repeatedly }\end{array}$ & $\begin{array}{l}\text { Slurring or } \\
\text { prominent slowing }\end{array}$ & $\begin{array}{c}\text { Marked } \\
\text { relaxation } \\
\text { (slack jaw) }\end{array}$ & $\begin{array}{l}\text { Glazed and marked ptosis } \\
\text { (more than half the eye) }\end{array}$ & 3 \\
\hline $\begin{array}{l}\text { Responds only after mild } \\
\text { prodding or shaking }\end{array}$ & $\begin{array}{l}\text { Few recognizable } \\
\text { words }\end{array}$ & - & - & 2 \\
\hline $\begin{array}{l}\text { Does not respond to mild } \\
\text { prodding or shaking }\end{array}$ & - & - & - & 1 \\
\hline
\end{tabular}

Table 2. Ramsey Sedation Scale.

Descriptions

Scores

Patient is anxious and agitated or restless, or both

Patient is co-operative, oriented, and tranquil

Patient responds to commands only

Patient exhibits brisk response to light glabellar tap or loud auditory stimulus

Patient exhibits a sluggish response to light glabellar tap or loud auditory stimulus 
pressures prevents EEG activation resulting from noxious electrical stimulation in rats. However, Hall et al ${ }^{21}$ found correlation with increasing doses of $\mathrm{N}_{2} \mathrm{O}$ from approximately 35 to $70 \%$. But Puri ${ }^{22}$ reported two cases with paradoxical changes in BIS during $\mathrm{N}_{2} \mathrm{O}$ administration.

Previous data regarding the use of BIS during $\mathrm{N}_{2} \mathrm{O}$ sedation remain insufficient. The aim of the current study was to assess any BIS changes during $\mathrm{N}_{2} \mathrm{O} / \mathrm{O}_{2}$ sedation in pediatric dentistry.

\section{MATERIALS AND METHODS}

This prospective research was performed in Gazi University Faculty of Dentistry. After obtaining Gazi University Faculty of Dentistry Ethic Committee approval and informed parental consent, 45 children having ASA physical status I, aged 7 to 12 years, weighing 21 to $33 \mathrm{~kg}$ (Table 1), and scheduled for primary teeth extraction were enrolled into the study. The participant were seen for their initial exam and it was determined that they definitely exhibited "definitely negative" behavior according to the Frankl Scale ${ }^{23}$ (Table 3). Exclusion criteria were refusal to have application of nasal hood or insufficient sedation (body movements, complaints, moaning, and crying). Sedation levels were evaluated and graded according to the OAA/ $\mathrm{S}^{4}$ (Table 1) and $\mathrm{RSS}^{7}$ (Table 2) scales.

\section{Sedation procedure}

Patients fasted two hours before sedation. No other premedication was given. Before sedation procedure, patients were assessed with RSS and then monitored with pulse oximetry (DatexOhmeda TuffSat@) and BIS (Aspect Medical Systems, A-2000 BIS $®$ ). A disposable BIS sensor was applied to the patient's forehead. Sedation was induced in standardized manner for all patients by nasal hood inhalation of $40 \%$ $\mathrm{N}_{2} \mathrm{O}$ in $\mathrm{O}_{2}$, and continued with $40-60 \% \mathrm{~N}_{2} \mathrm{O}$ in $\mathrm{O}_{2}$

Table 3. Frankl behavioral scale.

\begin{tabular}{lc}
\hline Descriptions & Score \\
\hline Refusal/Distress & 1 \\
Uncooperative/Reluctant & 2 \\
\hline Co-operative/Reserved & 3 \\
Interested/Enjoyed & 4
\end{tabular}

(inspired $\mathrm{N}_{2} \mathrm{O}$ fraction) with high fresh flow of 5 $L$ min $^{-1}$. The patient's heart rate (HR), peripheral oxygen saturation $\left(\mathrm{SpO}_{2}\right)$, and BIS measurements were recorded before ( $\mathrm{TO}=$ initial base values) and during the sedation (T1=third minute after initiation of $\mathrm{N}_{2} \mathrm{O}$ inhalation through a nasal hood and, respectively, $\mathrm{T} 2=4^{\text {th }} \mathrm{min}, \mathrm{T} 3=5^{\text {th }} \mathrm{min}, \mathrm{T} 4=6^{\text {th }}$ $\mathrm{min}$ ), and recovery period ( $\mathrm{T} 5=7^{\text {th }} \mathrm{min}, \mathrm{T} 6=8^{\text {th }} \mathrm{min}$ ) at one minute intervals. Paired measurements of BIS, RSS and OAA/S scores were obtained during the sedation period and recorded at one minute intervals. The investigator who performed the RSS and OAA/S assessments was blinded to the BIS values and $\mathrm{N}_{2} \mathrm{O} / \mathrm{O}_{2}$ concentration. At the end of the extraction, $\mathrm{N}_{2} \mathrm{O}$ inhalation was discontinued and $100 \% \mathrm{O}_{2}$ inhalation was performed for two minutes. Nasal hood and monitors were removed when the patient was alert and $\mathrm{HR}$ and $\mathrm{SpO}_{2}$ values were within the normal range. If any complication was observed, it was noted down.

\section{Dental treatment}

Topical anesthesia in the form of benzocaine gel $20 \%$ was applied to the dried mucosa adjacent to the tooth. Lidocaine $2 \%$ with 1:80000 adrenaline was then given in a standardized manner to each quadrant just before acquiring the BIS values ( $\mathrm{T} 2=4^{\text {th }}$ min after initiation of $\mathrm{N}_{2} \mathrm{O}$ inhalation through a nasal hood). Once analgesia had been achieved, the primary teeth were extracted $\left(\mathrm{T} 4=6^{\text {th }}\right.$ min after initiation of $\mathrm{N}_{2} \mathrm{O} / \mathrm{O}_{2}$ inhalation through a nasal hood).

\section{Statistical analysis}

SPSS version 15.0 for Windows was used for statistical analysis. The time course of the parameters during the T1-6 periods of the $\mathrm{BIS}, \mathrm{SpO}_{2}$ and HR and control sessions (TO) were evaluated using one-way analysis of variance (ANOVA) with repeated measurements and then the post hoc Tamhane test was performed if difference was significant. Using cross tabulation, a chi-square analysis was done between BIS levels and OAA/S scores in all time periods and correlation was calculated with Pearson Correlation Coefficient ( $r$ ) value $(r=0-0.25$ weak correlation, $0.251<r<0.500$ moderate correlation, $0.501<r<0.750$ strong correlation, $0.751<r<1.00$ most strong correlation). $\mathrm{P}<.05$ was considered as significant difference. 


\section{RESULTS}

Five patients who refused to have application of nasal hood were excluded from the study, and finally 40 patients were studied. Demographic properties are presented in Table 4. At baseline (TO) and during the sedation procedure (T1-T6) vital signs, including $\mathrm{SpO}_{2}$ and $\mathrm{HR}$ were recorded. The comparison of time dependent mean values of $\mathrm{SpO}_{2}$ and $\mathrm{HR}$ (T1, T2, T3, T4, T5 and T6 time points between TO sessions) were similar (P>.05) and statistically not different in normal clinical range.

The comparison of time dependent mean BIS values at T1, T2, T3, T4, T5 and T6 time points between $\mathrm{TO}$ sessions were similar and statistically not different $(P>.05)$. The mean value of BIS was 97.4. Before $\mathrm{N}_{2} \mathrm{O} / \mathrm{O}_{2}$ sedation, patients' RSS were determined as 1 but after the administration of $\mathrm{N}_{2} \mathrm{O} / \mathrm{O}_{2}$, at the T1-6 time points patients' RSS were 2 and OAA/S scores of patients' were 4 or 5 . During T1-6 time points all patients $(n=40)$ were relax and not reject the extractions. Although administration of $40-60 \% \quad \mathrm{~N} 20$ concentration is enough to provide sedation according to the $\mathrm{OAA} / \mathrm{S}$ scores in 40 children during the study period, no changes were obtained in BIS values. No correlation was found between BIS and the OAA/S scores levels at the T1-6 periods $(P=.126$,

Table 4. Demographic variables and duration of teeth extraction period.

\begin{tabular}{lc}
\hline Variables & \\
\hline Age (year) & $9.5 \pm 1.4$ \\
Weight $(\mathrm{kg})$ & $23.7 \pm 2.7$ \\
Sex (M/F) & $21 / 19$ \\
Extraction period (min) & $4.7 \pm 1.3$ \\
\hline
\end{tabular}

$r=0.1)$. Ramsay Sedation Scores and OAA/S correlations cannot be computed because at least one of the variables is constant. Figure 1 shows all the Pearson correlation coefficients between BIS levels and OAA/S scores during the study period. Pearson coefficient values indicate that weak correlation was obtained between BIS levels and OAA/S scores at all time periods $(r<0.25)$. There was no complication except nausea and vomiting at two patients during the recovery period.

\section{DISCUSSION}

In this research, children were clinically sedated with $40-60 \% \quad \mathrm{~N}_{2} \mathrm{O} / \mathrm{O}_{2}$ according to the RSS and OAA/S, but BIS values did not alter or paradoxical changes occur during the sedation procedure. Pediatric patients who are referred to the dental clinics are especially anxious with dental extractions. Administration of $\mathrm{N}_{2} \mathrm{O}$ in $\mathrm{O}_{2}$ is widely used to induce both analgesia and sedation and to improve patient cooperation during dental

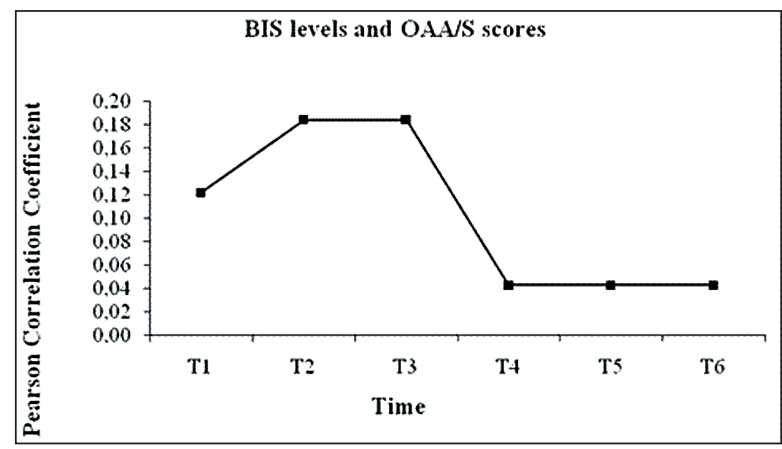

Pearson Correlation Coefficient $(r)$ value: $r=0-0.25$ weak correlation

Figure 1. Correlation legend between Bispectral Index (BIS) levels and Observer's Assessment of Alertness/ Sedation (OAA/S) scores.

Table 5. Significant HR values during study period.

\begin{tabular}{|c|c|c|c|c|c|c|c|}
\hline $\mathrm{T}_{0}$ & & $*$ & $*$ & $*$ & $*$ & & \\
\hline $\mathrm{T}_{1}$ & $*$ & & & $*$ & $*$ & $*$ & $*$ \\
\hline $\mathrm{T}_{2}$ & $*$ & & & & $*$ & $*$ & $*$ \\
\hline $\mathrm{T}_{4}$ & $*$ & $*$ & $*$ & $*$ & & & $*$ \\
\hline $\mathrm{T}_{5}$ & & $*$ & $*$ & $*$ & & & $*$ \\
\hline$T_{6}$ & & $*$ & $*$ & $*$ & $*$ & $*$ & \\
\hline
\end{tabular}

* : $P<.05$, indicates significant differences among $H R$ values during study period 
treatments. 1,2,24,25 Investigations were recognized thatBISscoreswere decreased by differentsedation or hypnosis techniques. ${ }^{6,9,12,26}$ Sadhasivam et al ${ }^{9}$ researched the validation of BIS for sedation with oral chloral hydrate, in meperidine+promethazine, IV midazolam+fentanyl, and IV pentobarbital+mida zolam+fentanyl, and it demonstrates that the BIS scores were significantly correlated with their paired $\mathrm{OAA} / \mathrm{S}$ scores. Religa et $\mathrm{al}^{27}$ conducted a study on pediatric patients, requiring dental restorations, between 3 to 6 years of age who received oral sedation with chloral hydrate or meperidine or hydroxyzine intraoperatively and $\mathrm{N}_{2} \mathrm{O} / \mathrm{O}_{2}$ was also administrated. A significant association was detected between observed patient behaviors during sedation and levels of sedation as measured by BIS. In an earlier study including 2 of 13 volunteers, BIS did not change with inspired $\mathrm{N}_{2} \mathrm{O}$ concentrations up to $50 \%$. The authors emphasized the stimulatory changes at lower and higher frequency ranges of EEG, which decreased at low $\mathrm{N}_{2} \mathrm{O}$ concentration. ${ }^{15}$ Ramesh at al ${ }^{28}$ suggested that $\mathrm{N}_{2} \mathrm{O}$ affects $\mathrm{BIS}$ values in patients under isoflurane anesthesia. Park et al $^{10}$ reported that $\mathrm{N}_{2} \mathrm{O}$ when used for sedation during epidural anesthesia does not have the expected effect on BIS signals. Two research showed that no change in BIS or Cerebral State Index value while the participants breathed $70 \%$ $\mathrm{N}_{2} \mathrm{O}$ in $\mathrm{O}_{2}$ although all of them lost consciousness clinically. 29,30 In their research on 22 healthy volunteers who were sedated by low $\mathrm{N}_{2} \mathrm{O}$, Hall et $\mathrm{al}^{21}$ reported that no correlation was found with $\mathrm{OAA} / \mathrm{S}$ and BIS. But a correlation was found when $\mathrm{N}_{2} \mathrm{O}$ concentration was increased from $35 \%$ up to $70 \%$. However Puri has reported paradoxical changes in BIS during $\mathrm{N}_{2} \mathrm{O}$ administration. ${ }^{22}$ Previous data regarding the use of BIS during $\mathrm{N}_{2} \mathrm{O}$ sedation remain insufficient. Probably, the conflicting results of various studies may be explained by the differential effects of $\mathrm{N}_{2} \mathrm{O}$ on EEG when administered at high/low concentrations or alone/in combination with sedative or anesthetics. In this research, the administration of $\mathrm{N}_{2} \mathrm{O}$ alone was adequate to perform teeth extraction but no alteration or paradoxical changes were observed at BIS values.

Nitrous oxide sedation is a reliable and practical method for pediatric dentistry. Nitrous oxide is effective and the anesthetic effect wears off quickly so there is no extended recovery time. ${ }^{1-3}$ In our study none of the patients were observed to exceed the level of 3 with respect to OAA/S which is described as patient who responds only after loud or repeated calling. However adequate sedation (OAA/S=4.5) was obtained at study group. Morse et $\mathrm{al}^{{ }^{31}}$ assessed the use of BIS monitoring in 22 patients undergoing conscious sedation with midazolam or midazolam plus ketamine for dental surgery and found that the BIS values remained close to baseline. In this research mean BIS value was 97.4 and it was similar to results of Morse et al.

In children, especially at the little age group, it is difficult to perform BIS and its devices. ${ }^{27}$ In our study group, children were aged between 7-12 years old. BIS and its devices were applied easily. Although the results of our study showed that $\mathrm{N}_{2} \mathrm{O}$ / $\mathrm{O}_{2}$ is enough to sedate children according to the RSS and OAA/S scores, we did not observe any significant changes BIS values. This means that using $\mathrm{N}_{2} \mathrm{O} / \mathrm{O}_{2}$ to sedate children undergoing dental extractions without any sedative agents does not require measuring the depth of sedation with BIS monitor.

\section{CONCLUSIONS}

Further investigations are needed for the validity and clinical applicability of BIS assessment with $\mathrm{N}_{2} \mathrm{O} / \mathrm{O}_{2}$ sedation at different concentrations or combined with other sedative drugs of in a larger pediatric population under dental treatments.

\section{REFERENCES}

1. www.aapd.org/media/Policies_Guidelines/G_Nitrous.pdf

2. Foley J. A prospective study of the use of nitrous oxide inhalation sedation for dental treatment in anxious children. Eur J Paediatr Dent 2005;6:121-128.

3. Foley J. Efficacy of nitrous oxide inhalation sedation and first permanent molar tooth extractions. SAAD Dig 2007;23:3-9

4. Motas D, McDermott NB, VanSickle T, Friesen RH. Depth of consciousness and deep sedation attained in children as administered by non-anaesthesiologists in a children's hospital. Pediatr Anaesth 2004;14:256-260.

5. Cravero JP, Blike GT. Review of pediatric sedation. Anesth Analg 2004;99:1355-1364.

6. Bruhn J, Myles P, Sneyd R, Struys M. Depth of anaesthesia monitoring: what's available, what's validated and what's next? Br J Anaesth 2006;97:85-94. 
7. Malviya S, Voepel-Lewis T, Tait AR. A comparison of observational and objective measures to differentiate depth of sedation in children from birth to 18 years of age. Anesth Analg 2006;102:389-394.

8. Chernik DA, Gillings $D$, Laine $H$, et al. Validity and reliability of the observer's assessment of alertness/sedation scale: study with intravenous midazolam. J Clin Psychopharmacol 1994;10: 244-251.

9. Sadhasivam S, Ganesh A, Robison A, Kaye R, Watcha MF. Validation of the bispectral index monitor for measuring the depth of sedation in children. Anesth Analg 2006;102:383388.

10. Park KS, Hur EJ, Han KW, Kil HY, Han TH. Bispectral index does not correlate with observer assessment of alertness and sedation scores during $0.5 \%$ bupivacaine epidural anesthesia with nitrous oxide sedation. Anesth Analg 2006;103:385-389.

11. Ramsay MA, Savege TM, Simpson BR, Goodwin R. Controlled sedation with alphaxalone-alphadolone. BMJ 1974;2:656-659.

12. McDermott NB, VanSickle T, Motas D, Friesen RH. Validation of the bispectral index monitor during conscious and deep sedation in children. Anesth Analg 2003;97:39-43.

13. Davidson A. Monitoring the anaesthetic depth in children: an update. Paediatr Anaesth 2007;20:236-243.

14. Murat I, Constant I. Bispectral index in pediatrics: fashion or a new tool? Pediatr Anesth 2005;15:177-180.

15. Rampil IJ, Kim JS, Lenhardt R, Negishi C, Sessler DI. Bispectral EEG index during nitrous oxide administration. Anesthesiology 1998;89:671-677.

16. Sandler NA, Sparks BS. The use of bispectral analysis in patients undergoing intravenous sedation for third molar extractions. J Oral Maxillofac Surg 2000;58:364-368.

17. Rodriguez RA, Hall LE, Duggan S, Splinter WM. The bispectral index does not correlate with clinical signs of inhalational anesthesia during sevoflurane induction and arousal in children. Can J Anaesth 2004;51:472-480.

18. Detsch O, Schneider G, Kochs E, Hapfelmeier G, Werner C. Increasing isoflurane concentration may cause paradoxical increases in the EEG bispectral index in surgical patients. Br J Anaesth 2000;84:33-37.

19. Constant I, Leport Y, Richard P, Moutard ML, Murat I. Agitation and changes of bispectral index and electroencephalographic-derived variables during sevoflurane induction in children: clonidine premedication reduces agitation compared with midazolam. Br J Anaesth 2004;92:504-511.

20. Leduc ML, Atherley R, Jinks SL, Antognini JF. Nitrous oxide depresses electroencephalographic responses to repetitive noxious stimulation in the rat. Br J Anaesth
2006;96:216-221.

21. Hall DL, Weaver J, Ganzberg S, Rashid R, Wilson S. Bispectral EEG index monitoring of high-dose nitrous oxide and low-dose sevoflurane sedation. Anesth Prog 2002;49:56-62.

22. Puri GD. Paradoxical changes in bispectral index during nitrous oxide administration. Br J Anaesth 2001;86:141142.

23. Frankl L, Hellman I. Symposium on child analysis. The Ego's participation in the therapeutic alliance. Int $J$ Psychoanal 1962;43:333-337.

24. Veerkamp JSJ, Gruythuysen RJM, van Amerongen WE. Dental treatment of fearful children using nitrous oxide. Part 3: anxiety during sequential visits. $J$ Dent Child 1993;60:175-181.

25. Nathan JE, Venham LL, West MS, Werboff J. The effects of nitrous oxide on anxious young pediatric patients across sequential visits: a double-blind study. ASDC J Dent Child 1988;55:220-230.

26. Wallenborn J, Kluba K, Olthoff D. Comparative evaluation of Bispectral Index and Narcotrend Index in children below 5 years of age. Paediatr Anaesth 2007;17:140-147.

27. Religa ZC, Wilson S, Ganzberg SI, Casamassimo PS. Association between bispectral analysis and level of conscious sedation of pediatric dental patients. Pediatr Dent 2002;24:221-226.

28. Ramesh VJ, Umamaheswara Rao GS. Does nitrous oxide affect bispectral index in patients under isoflurane anesthesia? J Neurosurg Anesthesiol 2006;18:267-268.

29. Barr G, Jakobsson JG, Owall A, Anderson RE. Nitrous oxide does not alter bispectral index: study with nitrous oxide as sole agent and as an adjunct to i.v. anaesthesia. $\mathrm{Br} J$ Anaesth 1999;82:827-830.

30. Anderson RE, Barr G, Jakobsson JG. Cerebral state index during anaesthetic induction: a comparative study with propofol or nitrous oxide. Acta Anaesthesiol Scand 2005;49:750-753.

31. Morse Z, Kaizu M, Sano K, Kanri T. BIS monitoring during midazolam and midazolam-ketamine conscious intravenous sedation for oral surgery. Oral Surg Oral Med Oral Pathol Oral Radiol Endod 2002;94:420-424. 